\title{
Marital Quality and Personal Well-Being: A Meta-Analysis
}

By: Christine M. Proulx, Heather M. Helms, $\underline{\text { Cheryl Buehler }}$

Proulx, C. M., Helms, H. M., \& Buehler, C. (2007). Marital quality and personal well-being: A meta- analysis. Journal of Marriage and Family, 69(3), 576-593.

Made available courtesy of Wiley-Blackwell:

http://onlinelibrary.wiley.com/doi/10.1111/j.1741-3737.2007.00393.x/abstract

\begin{abstract}
***Reprinted with permission. No further reproduction is authorized without written permission from Wiley-Blackwell and the National Council on Family Relations. This version of the document is not the version of record. Figures and/or pictures may be missing from this format of the document. $* * *$
\end{abstract}

\begin{abstract}
:
This study examines the association between marital quality and personal well-being using metaanalytic techniques. Effects from 93 studies were analyzed. The average weighted effect size $\mathrm{r}$ was .37 for cross-sectional and .25 for longitudinal effects. Results indicate that several variables moderate the association between marital quality and personal well-being, including gender, participants' marital duration, source of measurement, data collection year, and dependent variable. These results suggest that longitudinal effects are more likely to be uncovered when using standard measurement and that future research should use samples homogenous in marital length. The longitudinal finding that the strength of the association is stronger when personal well-being is treated as the dependent variable supports previous theorizing.
\end{abstract}

Keywords: marital quality | meta-analysis | well-being

\section{Article:}

The association between marital quality and personal well-being is demonstrated in the literature on marital relationships (Whisman, 2001). Individuals experiencing marital dissatisfaction tend to report higher levels of depressive symptomatology than those who are satisfied (Beach, Arias, \& O’Leary, 1986; Culp \& Beach, 1998). Marital satisfaction is associated positively with wives' life satisfaction (Freudiger, 1983) as well as with wives' and husbands' reports of global happiness (Glenn \& Weaver, 1981) and self-esteem (Voss, Markiewicz, \& Doyle, 1999). Longitudinal studies indicate that marital dissatisfaction predicts increases in depressive symptoms over time (Beach \& O’Leary, 1993a, 1993b; Fincham, Beach, Harold, \& Osborne, 1997), covaries with changes in depressive symptoms (Karney, 2001; Kurdek, 1998), and increases risk for a major depressive episode within a year (Whisman \& Bruce, 1999).

In a recent meta-analytic review of the literature on marital quality and personal wellbeing, Whisman (2001) focused on one component of personal well-being (i.e., depression) and 
found that marital quality was associated negatively with depressive symptoms for both men and women (weighted mean effect size $r=-.37$ and $r=-.42$, respectively) across 26 cross-sectional studies drawn from community samples. Although it appears that there is a significant negative link between marital satisfaction and depressive symptoms, this meta-analysis has several limitations. Longitudinal studies were excluded from the analysis, and only studies using standard measures of marital quality and depressive symptoms were included. Excluding longitudinal studies limits the conclusions that can be drawn about causality and also omits some of the most methodologically advanced studies. Further, limiting the analysis only to studies using standard measures excludes a variety of potentially important studies, particularly largescale, nationally representative surveys using single-item indicators (e.g., the National Survey of Families and Households, the Marital Stability Over the Life Course Survey). In addition, Whisman's meta-analysis focused only on depression and depressive symptomatology, providing no information about the association between marital quality and positive dimensions of personal well-being. Finally, moderators of the association between marital quality and depressive symptoms were not examined, limiting conclusions that can be drawn about the conditions under which marital quality and personal well-being are associated.

In the present study, we used meta-analytic techniques to summarize and organize data from 93 published studies assessing the concurrent and longitudinal link between marital quality and spouses' personal well-being. We address limitations of previous meta-analytic work and build on past reviews in several ways: (a) expand the definition of the independent and dependent variables to include both standard and nonstandard measures; (b) include multiple components of personal well-being (i.e., depressive symptoms, self-esteem, life satisfaction, global happiness, and physical health); (c) include studies using longitudinal designs; and (d) test for moderators of the association between marital quality and personal well-being.

\section{Conceptualization and literature review}

Marital predictors of well-being have been variously labeled marital quality, success, happiness, satisfaction, discord, adjustment, and well-being (Fincham \& Bradbury, 1987; Lewis \& Spanier, 1982). Empirical support exists linking these variables to spouses’ personal well-being. For example, both cross-sectional and longitudinal studies have found an association between spouses' personal well-being and marital love and conflict (Cox, Paley, Burchinal, \& Payne, 1999), marital satisfaction (Beach et al., 1986), and marital discord (Christian, O’Leary, \& Vivian, 1994). In the present study, the term marital quality is used to reflect the central dimension that the majority of these terms have in common: assessment of the cognitive, behavioral, or affective quality of the marriage. Furthermore, this conceptualization is in line with the operationalization of marital quality in the most frequently used measures of spouses' perceptions of marital quality (e.g., Dyadic Adjustment Scale, Marital Adjustment Test).

Previous meta-analytic work on marital satisfaction and personal well-being has conceptualized personal well-being as depressive affect or clinically diagnosed depression (Whisman, 2001). 
Understanding the link between marital quality and depressive symptomatology is important because both clinical and subclinical levels of depression pose a significant threat to individuals and society (Beach, Sandeen, \& O’Leary, 1990; Broadhead, Blazer, George, \& Kit Tse, 1990). Although both depression and depressive affect are included as dependent variables in this analysis and comprise the majority of relevant research, the conceptualization of personal wellbeing is expanded here to include additional indicators of personal well-being, such as selfesteem, physical health, global happiness, and life satisfaction. Thus, we expanded the definition of personal well-being to include those components that reach beyond the behavioral, emotional, and somatic descriptors characteristic of depressive symptoms, such as cognitive evaluations of one's life and physical indicators of well-being. This global conceptualization of personal wellbeing captures a broad array of the components of personal well-being most frequently assessed in the literature, recognizing that positive components of well-being are equally important to consider in the links between marital quality and personal well-being (Ross, 1995). By expanding the definition of personal well-being, we also recognize marital intervention as a potential starting point for bolstering positive dimensions of personal well-being and physical health in addition to alleviating depressive symptoms.

\section{Theoretical perspectives}

The literature examining the associations between marital quality and personal well-being presents mixed results regarding which variable functions as a precedent to the other. Several theoretical perspectives focusing specifically on the links between marital quality and depressive symptoms have helped to inform these findings, most notably the stress generation model (Davila, Bradbury, Cohan, \& Tochluk, 1997; Hammen, 1991) and the marital discord model of depression (Beach et al., 1990). The stress generation model suggests that individuals experiencing depressive symptoms, in part, cause their own stressful interactions with spouses, which in turn leads to further depressive symptoms (Davila et al.). This process of stress generation is an ongoing cycle that perpetuates both depressive symptoms and marital dissatisfaction. Although this model has received some support (Davila et al.) and is appealing in arguments for studying the "doubly developmental" course of marital quality and depressive symptoms in which changes in both constructs co-occur (Kurdek, 1998), methodological and analytic limitations make an adequate test of the model difficult (Beach, Davey, \& Fincham, 1999) and limit its applicability to much of the current research literature.

The hypothesis that marital quality leads to personal well-being is informed primarily by the marital discord model of depression (Beach et al., 1990). Studies focusing on clinically diagnosed patients suggest that they perceive, at least retrospectively, that their marital dissatisfaction preceded their depressive symptoms more often than the reverse (Birtchnell \& Kennard, 1983; O’Leary, Riso, \& Beach, 1990). Further, Beach and colleagues’ own work (Beach, Jouriles, \& O’Leary, 1985) suggested that over half of the couples in their study who were dissatisfied in their marriages also were characterized by mild to moderate levels of depressive symptomatology. Drawn from this clinical work on depressed individuals dissatisfied 
in their marriages, the theoretical model states that marital discord or dissatisfaction likely leads to increased risk of depression by limiting or removing available resources (e.g., spousal support), increasing spouses' stress, and increasing the levels of hostility experienced in the marriage. Specifically, Beach and colleagues suggest that marital dissatisfaction decreases positive marital elements such as couple cohesion, spousal dependability, and intimacy. Further, marital dissatisfaction is hypothesized to increase negative marital elements such as verbal and physical aggression and severe spousal denigration, criticism, and blame. Taken together, these marital behaviors are believed to have a negative effect on spouses’ personal well-being.

Although the emergence of Beach et al.'s (1990) model initially was meant to guide therapists working with depressed couples or individuals (Weissman, 1987), the model applies equally well to explaining pathways in the nonclinical population that connect marital discord or dissatisfaction to personal well-being. Current evidence from longitudinal studies suggests that there is a prospective relationship between marital quality and depressive symptoms (Beach, Katz, Kim, \& Brody, 2003; Fincham et al., 1997) controlling for initial depressive symptoms and intervening life events (Beach \& O’Leary, 1993a). Further evidence for the influence of marriage on personal well-being comes from research examining the impact of a positive marital event in improving or alleviating depressive symptoms. In their study of depressed spouses, Brown and colleagues found that a "fresh start" event or significant improvement in a marital problem was associated with recovery from a depressive episode, suggesting that changes in the marital relationship might precede or produce changes in depressive symptoms (Brown, Adler, \& Bifulco, 1988; Brown, Lemyre, \& Bifulco, 1992). Further support for this direction of effects is evidenced by the fact that treating individuals for their depressive symptoms does not appear to alleviate marital discord (Foley, Rounsaville, Weissman, Sholomaskas, \& Chevron, 1989).

Many of the marital processes that are hypothesized to influence depression in the marital discord model also are hypothesized to influence other personal well-being variables. Recent research suggests that it is the processes within marital relationships rather than the mere existence of another adult in the household that contribute to well-being. Supportive marriages appear to be linked with positive aspects of spouses' personal well-being, including physical health (Wickrama, Lorenz, Conger, \& Elder, 1997) and self-esteem (Voss et al., 1999), whereas conflict-ridden marriages and marriages characterized by low levels of cohesion appear to have a negative association with aspects of personal well-being such as self-esteem (Voss et al.).

\section{The present study}

The present study reviews the linkages between marital quality and personal well-being using meta-analytic techniques. Given theoretical considerations as well as previous research, we hypothesized that marital quality would be related positively to personal well-being, such that higher levels of marital quality would be related to more optimal levels of personal well-being both concurrently and over time. In addition, scholars have called for more research exploring the potential moderating variables of this relationship (Davila, Karney, Hall, \& Bradbury, 2003; 
Whisman, 2001). Thus, a primary goal of this study was to examine the role of several potential moderator variables. Selection of moderators was informed by (a) suggestions from the literature and key review articles; (b) conceptual, operational, and methodological considerations; and (c) key variables presented in the literature as factors that might explain or confound the relationship between marital quality and personal well-being. The following list, though not exhaustive of all potential moderators of this association, examines moderators that are central considerations when making choices about study design and measurement. Thus, we examined the moderating influence of sample, measurement, and design characteristics.

\section{Moderating role of sample characteristics}

Gender Although the marital discord model (Beach et al., 1990) focuses on differences in the prevalence of depressive symptoms between men and women, those who hypothesize gender differences in the strength of the association between marital quality and personal well-being point to socialization differences regarding interpersonal relationships and structural differences in the allocation of power in marriage (Allen \& Walker, 2000). It is suggested that women's personal well-being is tied more closely than men's to the emotional climate of their marriages (Thompson \& Walker, 1989) and that because wives typically have less power and status in their relationships, they might invest in them more than their husbands (Allen \& Walker). From this perspective, wives will be more vulnerable to marital dissatisfaction (Beach et al., 2003; Whisman, 2001) and perceive marital discord as a more significant stressor than will husbands (Dehle \& Weiss, 1998). Some researchers and theorists have suggested that women might accept more blame or responsibility if marital relationships become distressed, with increased levels of marital distress being perceived as a personal rather than a relational problem (Moberg \& Lazarus, 1990). These feelings of responsibility might lead women to experience increased depressive symptoms (Davila et al., 2003) and decreased self-esteem, life satisfaction, and physical health. Although the empirical evidence is mixed (e.g., Barnett, Brennan, Raudenbush, \& Marshall, 1994; Coyne \& Benazon, 2001; Davila et al., 2003), in his meta-analytic review of 26 cross-sectional studies, Whisman found that the association between marital dissatisfaction and depressive symptoms was stronger for women than it was for men. Thus, we hypothesized that the association between marital quality and personal well-being is stronger for women than for men both cross-sectionally and longitudinally.

Marital duration Length of marriage is another potential moderator of the relationship between marital quality and personal well-being. Marital quality declines after the first few years of marriage, experiencing the sharpest declines after the honeymoon period (Glenn, 1998; Vaillant \& Vaillant, 1993). In addition, currently half of all divorces occur within the first 7 years of marriage (Amato \& Cheadle, 2005). Even if couples in relatively young marriages are experiencing some of the problematic processes that erode perceptions of marital quality and lead to decreased levels of personal well-being, it might take some time for these effects to manifest themselves (Davila et al., 1997). Thus, we hypothesized that the association between marital quality and personal well-being is weaker for those studies sampling couples who have 
been married fewer than 8 years than for those including couples who are in more established marriages.

\section{Moderating role of measurement characteristics}

We treated the valence of the marital quality measurement as a potential moderator because the marital discord model of depression suggests it is the negative components associated with marital quality that erode levels of spouses’ personal well-being (Beach et al., 1990). We hypothesized that the strength of the association between marital quality and personal well-being is stronger when the valence of the marital quality measure is negative (e.g., conflict) than when it is positive (e.g., love). In addition, because previous meta-analytic research limited sampling to studies only using standard measurement, exploratory analyses were conducted to determine if marital quality and personal well-being measurement source (i.e., standard vs. nonstandard) moderated the relationship between marital quality and personal well-being.

\section{Moderating role of study design characteristics}

Study year Another potential moderator of the relationship between marital quality and personal well-being is the year in which the study was conducted. Given the increasing social acceptance of depressive symptoms, individuals participating in contemporary studies might be more likely to endorse such symptoms than in previous years. Further, given an increased emphasis on intimacy, love, and disclosure as the primary rewards of marriage (Cherlin, 2004; Giddens, 1992), spouses in contemporary marriages might have higher expectations for their relationship and their personal well-being might be influenced by unmet expectations. Thus, we hypothesized a positive relationship between study year and the strength of the association between marital quality and personal well-being, such that more contemporary studies will produce larger effect sizes.

Treatment of the dependent variable Drawing from the theoretical perspectives outlined thus far, we hypothesized that the causal direction leads more strongly from marital quality to personal well-being than vice versa. We anticipated that the longitudinal association between marital quality and personal well-being is stronger when personal well-being is the dependent variable than when marital quality is the dependent variable.

\section{Method}

\section{Study selection}

Several techniques were used to locate research studies. First, we searched two computerized databases_-PsychInfo and EbscoHost—using the following descriptors: marital satisfaction, marital quality, marital adjustment, marital discord, marital outcomes, depression, well-being, psychological well-being, self-esteem, life satisfaction, and marriage (or derivatives). Second, a manual search was conducted by searching the abstracts (or text of the article if the abstract did 
not indicate whether a measure of personal well-being was used) from 1980 through the second issue of 2005 of the following journals: Journal of Marriage and Family, Family

Relations, Journal of Family Issues, Journal of Social and Personal Relationships, Personal

Relationships, Journal of Family Psychology, and Journal of Personality and Social Psychology. Lastly, we supplemented the computerized and manual searches with literature reviews from the selected articles, as well as the reference lists of key review articles in the fields of family studies and family psychology. Dissertations and unpublished reports were excluded because they had not been reviewed by independent peer evaluators.

Inclusion criteria for studies were as follows: (a) the work was published in English, (b) the association between marital quality and some aspect of individual well-being was examined, (c) the assessment of marital quality and personal well-being was consistent with the conceptual definitions stated earlier, (d) at least one usable statistical measure of association was calculated, (e) the study was published since 1980, and (f) the sample or subsample in the study was comprised only of married individuals.

Most studies contributed a single independent sample or several independent subsamples. Some longitudinal studies, however, included results treating both marital quality and personal wellbeing as dependent variables. In these cases, an effect size estimate from both was included for the moderator analyses. Occasionally, two studies used the same data set. We included both studies in the analysis if they used different subsamples, and we pooled studies when they used the same data set but different independent and dependent variables $(n=4)$. For those cases in which two or more studies used the same sample or the same independent or dependent variables, we retained only the study with the largest sample size. These selection procedures resulted in the review of 93 studies (66 cross-sectional, 27 longitudinal), resulting in 66 crosssectional effect sizes and 24 longitudinal effect sizes (because of pooling studies with the same data set).

\section{Calculation of effects}

The primary effect used in this study is the product-moment correlation $(r)$. The product-moment correlation was calculated using formulas described by Rosenthal (1991). Beta coefficients were adjusted using the procedures outlined by Peterson and Brown (2005). One study reported only that an association was nonsignificant. In this case, we estimated $r$ given the study sample size and a maximum value of $p>.05$, a conservative estimate of the actual effect. Marital quality measures were coded so that a higher score indicated greater marital quality. Similarly, a higher personal well-being score indicated more optimal personal well-being.

Studies contributing more than one effect raised the issue of nonindependence among sampling units. A single pooled effect size from each study was calculated (Rosenthal, 1991). For example, marital quality was assessed by three measures in the study by Johnson and Booth (1990) — marital happiness, thoughts about divorce, and quality of marital communication —and 
each was linked with individual well-being. Thus, the individual $r$ s for the association between these three aspects of marital quality and personal well-being were calculated and averaged to obtain one aggregate effect. For the moderator analyses, however, effects were aggregated within categories of selected moderators (e.g., Glass, McGaw, \& Smith, 1981). For example, we examined the moderating role of gender, and therefore, effects from men and women in the same sample were examined separately in the moderator analyses rather than aggregated. This procedure resulted in a total of 137 cross-sectional effects and 78 longitudinal effects for the moderator analyses.

\section{Study characteristics coded for each effect}

For the purposes of the moderator analyses, each relevant effect and its associated characteristics were coded. Table 1 lists all codes and the number of effects coded in their respective categories. All effects and their associated characteristics were coded by the first author. To assess the reliability of our coding, the second and third authors coded the effects and characteristics of a random $20 \%$ of the articles $(n=19)$. Percent agreement was $96 \%$ averaged across all moderators. For categorical variables, Cohen's kappa was .91. For continuous variables (i.e., year of data collection), the intraclass correlation was .97. Disagreements in coding were resolved through discussion, and resulting changes in coding rules were applied across all effect coefficients.

\section{[Table 1 Omitted]}

\section{Calculation of mean effects}

Prior to analysis, effects were transformed to $z$ scores using Fischer's $r$ to $z$ transformation (Rosenthal, 1991; Shadish \& Haddock, 1994). After significance testing, mean effect sizes were transformed back from $z$ to $r$. The homogeneity coefficient $H$ also was calculated for the crosssectional and longitudinal studies. A significant $H$ allowed for the rejection of the null hypothesis that all studies share a common population effect size and the examination of moderating variables that might account for some of the variability in effects across studies (Hedges \& Olkin, 1985).

\section{Results}

\section{Overall effect between marital quality and personal well-being}

A significant $H$ was obtained for the cross-sectional and longitudinal studies, $H(66)=$ $1,741.61, p<.0001$ and $H(24)=972.48, p<.0001$, respectively, indicating variability across effects. Thus, a random effects model, in which the effect size parameters are treated as a random sample from a larger population of effect parameters was used in calculating the mean effect sizes. Using a random effects model allows inferences to be made about the parameters of a population of studies larger than the set of observed studies gathered in the present analysis (Hedges \& Vevea, 1998). The 66 cross-sectional effects ranged from .04 to .98, and the 24 
longitudinal effects ranged from .01 to .51. The weighted mean effect size for cross-sectional studies was $r=.37$ (95\% confidence interval $=.33 \leq \mu \leq .42$ ). This result suggests that, across all available cross-sectional studies, the concurrent association between marital quality and personal well-being is positive and significant. The weighted mean effect size for longitudinal studies was $r=.25$ ( $95 \%$ confidence interval $=.20 \leq \mu \leq .30)$. Thus, as hypothesized, marital quality was associated positively and significantly with personal well-being in longitudinal studies. Using Cohen's (1977) criteria to assess the magnitude of this relationship, the cross-sectional mean effect size is moderate in strength, whereas the longitudinal mean effect size is small to moderate.

Undoubtedly, this meta-analysis missed some published studies. The fail-safe $N$ was calculated to assess the number of studies reporting null results needed to reduce the overall mean effect size to nonsignificance (Rosenthal, 1984). The fail-safe $N$ for the cross-sectional sample was 186; for the longitudinal sample, it was 3 . Although it is unlikely that 186 cross-sectional studies reporting null results exist, it is quite possible that 3 longitudinal studies reporting null results exist, and thus, the finding that marital quality and personal well-being are related positively appears more robust for cross-sectional effects than for longitudinal effects. A funnel plot was created to estimate the potential bias against small sample sizes and insignificant results (Light \& Pillemer, 1984). An inverted funnel shape resulted for both subsamples of studies, suggesting that little to no bias existed against small sample sizes or nonsignificant results. A statistical analogue to the funnel plot also was calculated. A weighted regression analysis was conducted in which effect size was regressed on the standard error of the effect size and the weights were inversely proportional to the variance of the effect size (Sterne, Egger, \& Smith, 2001). For both cross-sectional and longitudinal studies, the beta coefficients were small, offering further evidence that sampling bias was minimal $(b=1.90, p=.05$ and $b=1.12, p=.19$ for cross-sectional and longitudinal studies, respectively), though the $p$ value for cross-sectional studies suggests that some sampling bias might be present.

\section{Moderating effects of sample characteristics}

A hierarchical mixed effects weighted regression model was used to determine which variables moderated the association between marital quality and personal well-being. Mixed effects models are used when the mean weighted effect size is random but moderators are fixed, and inferences are drawn only from those categories that are coded (Overton, 1998). Variance inflation was examined to check for multicollinearity, and all variance inflation values were within acceptable limits. With the exception of year, which was treated as a continuous variable, all moderators were categorical, and dummy codes were created. The reference categories were as follows: (a) gender: men only, (b) marital duration: married 8 years or more, (c) marital quality and personal well-being measurement source: nonstandard, (d) valence of marital quality measurement: negative, and (e) for longitudinal studies, the dependent variable conceptualization: marital quality. For the longitudinal analysis, only five studies included effects using a sample of men and women combined. To avoid drawing inaccurate conclusions, 
we only interpret the contrast on the basis of male and female samples. In addition, because some studies did not report marital duration of the sample or included couples heterogeneous in marital duration, a mixed category was created for marital duration. Although included in the analyses, contrasts using this category are not presented because of the difficulty of meaningfully and accurately interpreting a coefficient drawn from heterogeneous marital duration.

Results for the cross-sectional hierarchical regression analysis are in Table 2; results for the longitudinal analysis are in Table 3. A summary of all results appears in Table 4. Sample characteristics explained $11 \%$ and $2 \%$ of the variance in the dependent variable for crosssectional and longitudinal analyses, respectively. The cross-sectional association between marital quality and personal well-being was moderated by gender and marital duration. The longitudinal association was moderated by marital duration.

\section{[Table 2 Omitted]}

\section{[Table 3 Omitted]}

\section{[Table 4 Omitted]}

Gender Gender was a significant moderator for cross-sectional studies, such that, when controlling for all other potential moderators, the concurrent association between marital quality and personal well-being was stronger for samples of only women than for samples of only men.

Length of marriage When controlling for all other potential moderators, the cross-sectional association between marital quality and personal well-being was stronger for marriages of fewer than 8 years duration than for those 8 years or more in duration. The opposite was true for longitudinal studies, such that the association between marital quality and personal well-being was weaker for marriages of fewer than 8 years duration than it was for marriages of 8 years or more.

\section{Moderating effects of measurement characteristics}

Adding measurement characteristics to the model explained an additional $6 \%$ and $46 \%$ of variance in the dependent variable for cross-sectional and longitudinal analyses, respectively. In the final model, the cross-sectional association between marital quality and personal well-being was moderated by the marital quality measurement source. The longitudinal association between these variables was moderated by whether the marital quality measure assessed a positive or negative component and by the marital quality and personal well-being measurement source.

Valence of marital quality measure The longitudinal association between marital quality and personal well-being was stronger when the valence of the marital quality measure was negative (e.g., conflict) than when it was positive (e.g., satisfaction). 
Marital quality and well-being source When marital quality was assessed by standard (e.g., Dyadic Adjustment Scale, Marital Adjustment Test) rather than nonstandard measures (e.g., single-item indicator, latent variables in structural equation modeling [SEM]), the cross-sectional and longitudinal association between marital quality and personal well-being was stronger. When personal well-being was assessed by standardized measures (e.g., Beck Depression Inventory, Center for Epidemiological Studies-Depression Scale) rather than by nonstandard measures, only the longitudinal association between marital quality and personal well-being was stronger.

\section{Moderating effects of study design characteristics}

The addition of the study design characteristics explained no further variance in the crosssectional model and an additional $4 \%$ of variance in the longitudinal model. The longitudinal association between marital quality and personal well-being was moderated by the year the data were collected as well as by the treatment of the dependent variable.

Year of data collection For longitudinal studies, there was a positive association between the strength of the association between marital quality and personal well-being and year of study, such that the more current the study, the stronger the association.

Dependent variable As hypothesized, the longitudinal association between marital quality and personal well-being was stronger when personal well-being rather than marital quality was treated as the dependent variable.

\section{Discussion}

The association between marital quality and personal well-being has interested family scholars for decades. Although previous meta-analytic reviews suggest that the cross-sectional association between marital quality and depressive symptoms is moderate in strength (Whisman, 2001), the purpose of this meta-analysis was to extend previous work and provide a comprehensive examination of the cross-sectional and longitudinal link between marital quality and personal well-being, including the positive dimensions of personal well-being and the potential moderators of this association. The results, drawn from 66 cross-sectional and 27 longitudinal studies, confirm that marital quality is related positively to personal well-being, both concurrently and over time. Higher levels of marital quality are associated with more optimal levels of personal well-being. Several moderating effects for sample, study, and design characteristics also were significant, including gender, participants' length of marriage, the source of both marital quality and personal well-being measurement, the valence of the marital quality measurement, the year of data collection, and the treatment of the dependent variable.

\section{Theoretical considerations}

Previous meta-analytic work was limited to cross-sectional studies and thus unable to provide evidence in support of causal theoretical models of the association between marital quality and 
spouses’ personal well-being (Whisman, 2001). The results of this study, however, included longitudinal research and supported the marital discord model of depression. The strength of the association between marital quality and personal well-being was significantly stronger for those longitudinal studies in which personal well-being was the dependent variable than for those in which marital quality was treated as the dependent variable. Further, this meta-analytic review extended the theoretical model by suggesting that marital quality also is related to positive components of personal well-being.

Although the results of this meta-analysis support and extend the marital discord model of depression, we are unable to draw conclusions about the specific processes in marriage that are related to personal well-being. Further, many of the longitudinal studies included in this metaanalysis consisted of only two waves of data. It is possible that with longitudinal designs spanning more than two waves, the nuances in how marital quality is linked with personal wellbeing could be revealed. It also is possible that multiple-wave designs might reveal a cyclical pattern in the relationship between marital quality and personal well-being. Researchers using the stress generation model of depression suggest such a process, in that increases in depressive symptoms predict declines in the quality of intimate relationships such as marriage, which then leads to further increases in depressive symptoms (Davila et al., 1997). By taking advantage of recent methodological advances in the study of change within marriage (e.g., Bryk \& Raudenbush, 1992), future research can refine the literature supporting or refuting theoretical models of the relationship between marital quality and personal well-being.

Had we focused the present meta-analysis on chronic disorders or other related psychiatric disorders, rather than community or mixed samples, our causal findings might have differed. Several researchers have suggested that history of a major depressive disorder as early as adolescence can be linked to later marital quality (Gotlib, Lewinsohm, \& Seeley, 1998). This finding suggests that severe psychiatric disorders might be related to interpersonal difficulties that result in poor marital quality between spouses. This line of reasoning reiterates the importance of a developmental perspective tracing the course of depressive symptomatology, severe psychiatric disorders, and marital quality when studying the links among these variables.

\section{Moderators of the association between marital quality and personal well-being}

Of the sample characteristics examined, both gender and the length of participants' marriage emerged as significant moderators of the association between marital quality and personal wellbeing. We found partial evidence to support our hypothesis that gender would moderate the association between marital quality and personal well-being. Similar to previous meta-analytic work (i.e., Whisman, 2001), we found that gender emerged as a significant moderator of the cross-sectional association between marital quality and personal well-being. Specifically, the concurrent association between marital quality and personal well-being was stronger for samples of women only than it was for samples of men only. We did not, however, find support for the gender hypothesis for the longitudinal association between marital quality and personal well- 
being. Results of the longitudinal research literature are mixed (Beach et al., 2003) and combined with the results of this meta-analysis suggest that the strength of the association between marital quality and personal well-being might not differ consistently over time for husbands and wives. These mixed results suggest that it is premature to assume that the relational processes underlying this link, both concurrently and over time, are similar for wives and husbands. Thus, we cannot rule out the likelihood that the processes through which marital quality is associated with personal well-being differ for men and women. Feminist researchers have long argued that men and women experience marriage differently (Bernard, 1972) and that within marriage gender is created and sustained through everyday interaction (Thompson \& Walker, 1989). It is this everyday interaction that might help explain why the concurrent but not the longitudinal association between marital quality and personal well-being is stronger for wives than for husbands. If, as some researchers have suggested, women's personal well-being is tied more closely to the daily emotional climate of their marriages (Thompson \& Walker), to which wives are particularly attuned, there might be a stronger concurrent association between marital quality and personal well-being for them than for husbands, but perhaps marital experiences over time are equally likely to predict both husbands’ and wives’ personal well-being.

Partial support was found for our hypothesis regarding marital duration, in that the longitudinal association between marital quality and personal well-being was weaker for marriages of fewer than 8 years than it was for marriages of 8 or more years. Contrary to the hypothesis, we found that the cross-sectional association between marital quality and personal well-being was stronger for marriages of fewer than 8 years' duration than it was for marriages 8 or more years in duration. These findings suggest that the strength of the association between marital quality and personal well-being differs at various points in the course of marriage, with a different pattern of findings emerging for cross-sectional and longitudinal studies. One possible explanation for the longitudinal finding is that spouses in more established marriages might be experiencing greater levels of the negative processes by which marital quality is thought to influence personal wellbeing over time. It also is possible that in samples of newlyweds, it takes longer to see the continued effects of marital processes on well-being. If, as Beach et al. (1990) suggest, the influence of marital satisfaction on personal well-being occurs through removing spousal resources and increasing negative marital behavior, it might be that for newlywed marriages, the establishment of these clear marital patterns and their influence on personal well-being has yet to emerge.

The cross-sectional finding suggests that the longer the spouses are married, the weaker the concurrent association between marital quality and personal well-being, which is contrary to our hypothesis. This might be explained partially by a self-selection bias, in that longer term marriages have made it past the most common peaks for divorce. Thus, it is possible that those spouses who have divorced are differentially affected by marital quality than those who stay in their marriages. For example, it might be that when the marriage fails to measure up, those for whom the marital relation is closely tied to a sense of self are more likely to dissolve their 
marriage. Lower marital quality might be more costly if it is central to one's sense of self and identity. It also might be that the longer spouses are married, the less sensitive they become to negativity in their marriages and the more likely additional contemporaneous issues are to be associated with personal well-being. For example, the quality of competing roles such as employee, parent, or caregiver to the elder generation during the middle years of marriage might have a strong association with personal well-being, potentially moderating the association between marital quality and personal well-being during those years. Thus, we suggest that future research pay increasing attention to the social contexts in which marriages are embedded as well as the workplace and its policies, all of which might influence the association between marital quality and personal well-being (Bradbury \& Karney, 2004; Helms \& Demo, 2005; Huston, 2000).

When examining the variance explained by our models, measurement characteristics appear to explain the greatest amount of variance for both cross-sectional and longitudinal effect sizes. We found partial support for our hypotheses regarding the moderating role of measurement characteristics. When marital quality was assessed via a standard measure, either concurrently or over time, the association between marital quality and personal well-being was stronger than when a nonstandard measure was used. This same pattern emerged for personal well-being measurement but only for longitudinal studies. These results suggest that standard measures of both marital quality and personal well-being might better assess the components of marital quality and personal well-being that are associated with each other than do nonstandard or single-item measures. We also found partial support for our hypothesis that the strength of the association between marital quality and personal well-being is stronger when the valence of the marital quality component is negative than when it is positive, although this held true only for the longitudinal association. As suggested by the marital discord model of depression (Beach et al., 1990), it appears that, over time, spouses' perceptions of the negative components of marriage erode their perceptions of personal well-being. For example, components of the marriage such as dissatisfaction, discord, or conflict appear more strongly associated with spouses' personal well-being over time than do components such as love, satisfaction, or harmony.

Characteristics of study design also influenced the strength of the association between marital quality and personal well-being. We found support for the hypothesis that more contemporary studies would produce stronger effect sizes than older studies but only for the longitudinal association between marital quality and personal well-being. Given an increased emphasis on intimacy, love, and disclosure as the primary rewards of marriage (Cherlin, 2004; Giddens, 1992), spouses in contemporary marriages might have higher expectations for their relationship and their personal well-being, at least over time, and might be influenced by unmet expectations.

As hypothesized, the strength of the association between marital quality and personal well-being was stronger for longitudinal studies predicting personal well-being than it was for those predicting marital quality. This finding offers further support for the marital discord model of 
depression (Beach et al., 1990) and the direction of effects it hypothesizes. Future research should continue to examine the specific mechanisms that the model suggests might be operating. For example, the theoretical model states that marital discord or dissatisfaction likely leads to increased risk of depression/depressive symptoms by limiting or removing available resources (e.g., spousal support), increasing spouses' stress, and increasing the levels of overt hostility experienced in the marriage, but little research to date has examined these processes in detail.

The finding that several of the results differed depending on whether the cross-sectional or longitudinal effects were analyzed is substantively and theoretically intriguing and warrants further discussion. The majority of studies located for this study on the association between marital quality and personal well-being were cross-sectional, which limits the ability to test, confirm, or refute causal theory, as well as to uncover the processes behind this association. Marriage is dynamic and cross-sectional studies only capture a snapshot of the processes that occur within it. Further, there is evidence that personal well-being might wax and wane over time (Davila et al., 2003), and thus, the same limitation holds when studying personal well-being using cross-sectional designs. Studies relying on cross-sectional designs to assess associations among variables are limited to conclusions about the extent to which they co-occur. Given that this concurrent association is well established in the literature, it appears the time has come to move beyond cross-sectional designs and to implement research that will explain how this association develops and the contexts within which this association might vary over the life course.

\section{Directions for future research}

The meta-analysis described here found that spouses' own marital quality is associated with their own personal well-being and the longitudinal link between marital quality and personal wellbeing is stronger when personal well-being is treated as the dependent variable. This metaanalysis also highlights the need for additional longitudinal research on the association between marital quality and personal well-being, for both theoretical and empirical reasons. For example, it remains unknown how changes in marital quality might be linked with changes in personal well-being or whether the two variables change in the same manner. The few studies exploring changes in this association suggest that marital quality might follow a more linear decline, whereas personal well-being waxes and wanes around an individual's level of emotionality, such as a given level of negative affectivity (Davila et al., 2003; Kurdek, 1998). In addition, recent

research suggests that spouses might experience crossover effects whereby their spouse's marital quality influences their own personal well-being (Beach et al., 2003). The number of studies assessing spousal crossover effects was not large enough to warrant a separate meta-analysis, but as this literature develops, meta-analytic work has the potential to reveal more about the dyadic nature of this link (Beach et al.). Thus, future studies should sample both members of the marital dyad and pay continued attention to possible gender differences and similarities. The results from this meta-analysis suggest that sampling couples homogenous in marital duration is necessary as it appears that marital duration moderates the association between marital quality and personal 
well-being. Further, researchers should pay attention to the measurement and design choices made when conceptualizing studies examining the associations between marital quality and personal well-being, as both measurement and design characteristics emerged as significant moderators in the present study.

Although the present study offers an emerging portrait of the association between marital quality and personal well-being both cross-sectionally and over time, it also highlights what remains unknown about the relation between these two variables. The evidence accumulated in this metaanalysis suggests that the higher one's level of marital quality, the better one's personal wellbeing. We need a more thorough understanding, however, of how marital quality contributes to spouses' personal well-being and how the association between these two variables might change over the course of a marriage. We also need a better understanding of the contextual moderators of this association. We believe that the literature on the association between marital quality and personal well-being will be strengthened by increased attention to the longitudinal course of the association as well as potential methodological limitations in study design, sampling, and analysis. Efforts toward increasing the depth of our knowledge in this area will result in a body of research that better unveils the complexities of marital relationships and the ways in which they are associated with spouses' personal well-being.

\section{Note}

Work on this manuscript was completed at the University of North Carolina at Greensboro. Parts of this article were presented at the annual meeting of the National Council on Family Relations, Minneapolis, MN, November 2006.

\section{References}

References marked with an asterisk indicate studies included in the meta-analysis.

Allen, K. R., \& Walker, A. J. (2000). Constructing gender in families. In R.

M.Milardo \& S.Duck (Eds.), Families as relationships (pp. 1 -17). Chichester, UK: Wiley.

Amato, P. R., \& Cheadle, J. (2005). The long reach of divorce: Divorce and child well-being across three generations. Journal of Marriage and Family, 67, 191 - 206.

*Assh, S. D., \& Byers, E. S. (1996). Understanding the co-occurrence of marital distress and depression in women. Journal of Social and Personal Relationships, 13, 537 - 552.

*Barnett, R. C., Brennan, R. T., Raudenbush, S. W., \& Marshall, N. L. (1994). Gender and the relationship between marital-role quality and psychological distress. Psychology of Women Quarterly, 18, 105 - 127.

*Barnett, R. C., \& Gareis, K. C. (2002). Full-time and reduced-hours work schedules and marital quality. Work and Occupations, 29,364 - 379. 
*Barnett, R. C., Raudenbush, S. W., Brennan, R. T., Pleck, J. H., \& Marshall, N. L. (1995). Changes in job and marital experiences and change in psychological distress: A longitudinal study of dual-earner marriages. Journal of Personality and Social Psychology,69, 839 - 850.

*Baruch, G. K., \& Barnett, R. (1986). Role quality, role involvement, and psychological wellbeing in midlife women. Journal of Personality and Social Psychology, 51, 578 - 585.

*Basco, M. R., Prager, K. J., Pita, J. M., Tamir, L. M., \& Stephens, J. J. (1992). Communication and intimacy in the marriage of depressed marriages. Journal of Family Psychology, 6, 184 194.

*Bauserman, S. K., Arias, I., \& Craighead, W. E. (1995). Marital attributions in spouses of depressed patients. Journal of Psychopathology and Behavioral Assessment, 17, 231 - 249.

*Beach, S. R. H., Arias, I., \& O’Leary, K. D. (1986). The relationship of marital satisfaction and social support to depressive symptomatology. Journal of Psychopathology and Behavioral Assessment, 8, 305 - 317.

Beach, S. R. H., Davey, A., \& Fincham, F. D. (1999). The time has come to talk of many things: A commentary on Kurdek (1998) and the emerging field of marital processes in depression. Journal of Family Psychology, 13, 663 - 668.

Beach, S. R. H., Jouriles, E. N., \& O’Leary, K. D. (1985). Extramarital sex: Impact on depression and commitment in couples seeking marital therapy. Journal of Sex and Marital Therapy, 11, 99 - 108.

*Beach, S. R. H., Katz, J., Kim, S., \& Brody, G. H. (2003). Prospective effects of marital satisfaction on depressive symptoms in established marriages: A dyadic model. Journal of Social and Personal Relationships, 20, 355 - 371.

*Beach, S. R. H., \& O’Leary, K. D. (1993a). Dysphoria and marital discord: Are dysphoric individuals at risk for marital maladjustment? Journal of Marital and Family Therapy, 19, 355 368.

*Beach, S. R. H., \& O’Leary, K. D. (1993b). Marital discord and dysphoria: For whom does the marital relationship predict depressive symptomatology? Journal of Social and Personal Relationships, 10, $405-420$.

Beach, S. R. H., Sandeen, E. E., \& O’Leary, K. D. (1990). Depression in marriage: A model for etiology and treatment. New York: Guilford Press.

Bernard, J. (1972). The future of marriage. New York: World. 
Birtchnell, J., \& Kennard, J. (1983). Does marital maladjustment lead to mental illness? Social Psychiatry, 18, $79-88$.

*Booth, A., \& Johnson, D. R. (1994). Declining health and marital quality. Journal of Marriage and the Family, 56, 218 - 223.

Bradbury, T. N., \& Karney, B. R. (2004). Understanding and altering the longitudinal course of marriage. Journal of Marriage and Family, 66, 862 - 879.

Broadhead, E. W., Blazer, D. G., George, L. K., \& Kit Tse, C. (1990). Depression, disability days, and days lost from work in a prospective epidemiological survey. Journal of the American Medical Association, 264, 2524 - 2528.

*Brodbar-Nemzer, J. Y. (1986). Marital relationships and self-esteem: How Jewish families are different. Journal of Marriage and the Family, 48, 89 - 98.

Brown, G. W., Adler, Z., \& Bifulco, A. (1988). Life events, difficulties and recovery from chronic depression. British Journal of Psychiatry,152, 487 - 498.

Brown, G. W., Lemyre, L., \& Bifulco, A. (1992). Social factors and recovery from anxiety and depressive disorders: A test of specificity.British Journal of Psychiatry, 161, 44 - 54.

Bryk, A. S., \& Raudenbush, S. W. (1992). Hierarchical linear models: Applications and data analysis methods. Newbury Park, CA: Sage.

*Cano, A., O’Leary, K. D., \& Heinz, W. (2004). Short-term consequences of severe marital stressors. Journal of Social and Personal Relationships, 21, 419 - 430.

Cherlin, A. J. (2004). The deinstitutionalization of American marriage. Journal of Marriage and Family, 66, 848 - 861.

*Christian, J. L., O’Leary, D. K., \& Vivian, D. (1994). Depressive symptomatology in mutually discordant women and men: The role of individual and relationship variables. Journal of Family Psychology, 8, $32-42$.

*Cleary, P. D., \& Mechanic, D. (1983). Sex differences in psychological distress among married people. Journal of Health and Social Behavior, 24, 111 - 121.

*Cohan, C. L., \& Bradbury, T. N. (1997). Negative life events, marital interaction, and the longitudinal course of newlywed marriage.Journal of Personality and Social Psychology, 73, $114-128$.

Cohen, J. (1977). Statistical power analysis for the behavioral sciences. London: Academic. 
*Cotton, S. R., Burton, R. P. D., \& Rushing, B. (2003). The mediating effects of attachment to social structure and psychosocial resources on the relationship between marital quality and psychological distress. Journal of Family Issues, 24, 547 - 577.

*Cox, M. J., Paley, B., Burchinal, M., \& Payne, C. C. (1999). Marital perceptions and interactions across the transition to parenthood.Journal of Marriage and the Family, 61, 611 625.

Coyne, J. C., \& Benazon, N. R. (2001). Not agent blue: Effects of marital functioning on depression and implications for treatment. InS. R. H.Beach (Ed.), Marital and family processes in depression: A scientific foundation for clinical practice (pp. 25 - 43). Washington, DC: American Psychological Association.

*Coyne, J. C., \& Smith, D. A. F. (1991). Couples coping with a myocardial infarction: A contextual perspective on wives' distress.Journal of Personality and Social Psychology, 61, $404-412$.

*Crowther, J. H. (1985). The relationship between depression and marital maladjustment: A descriptive study. Journal of Nervous and Mental Disease, 173, 227 - 231.

*Culp, L. N., \& Beach, S. R. H. (1998). Marriage and depressive symptoms: The role and bases of self-esteem differ by gender.Psychology of Women Quarterly, 22, 647 - 663.

*Davies, P. T., Dumenci, L., \& Windle, M. (1999). The interplay between maternal depressive symptoms and marital distress in the prediction of adolescent development. Journal of Marriage and the Family, 61, 238 - 254.

*Davila, J., Bradbury, T. N., Cohan, C. L., \& Tochluk, S. (1997). Marital functioning and depressive symptoms: Evidence for a stress generation model. Journal of Personality and Social Psychology, 73, 849 - 861.

*Davila, J., Karney, B. R., Hall, T. W., \& Bradbury, T. N. (2003). Depressive symptoms and marital satisfaction: Within-subject associations and the moderating effects of gender and neuroticism. Journal of Family Psychology, 17, 537 - 570.

*Dehle, C., \& Weiss, R. L. (1998). Sex differences in prospective associations between marital quality and depressed mood. Journal of Marriage and the Family, 60, 1002 - 1011.

*Dehle, C., \& Weiss, R. L. (2002). Associations between anxiety and marital adjustment. Journal of Psychology, 136, 328 - 338.

*Dimitrovsky, L., Levy-Shiff, R., \& Schattner-Zanany, I. (2002). Dimensions of depression and perfectionism in pregnant and nonpregnant women: Their levels and interrelationships and their relationship to marital satisfaction. Journal of Psychology, 136,631 - 646. 
*Dimitrovsky, L., Schapira-Beck, E., \& Itskowitz, R. (1994). Locus of control of Israeli women during the transition to marriage. Journal of Psychology, 128, 537 - 545.

*Doucet, J., \& Aseltine, R. H., Jr. (2003). Childhood family adversity and the quality of marital relationships in young adulthood.Journal of Social and Personal Relationships, 20, 818 - 842.

*Feeney, J., Alexander, R., Noller, P., \& Hohaus, L. (2003). Attachment insecurity, depression, and the transition to parenthood.Personal Relationships, 10, $475-493$.

*Feldman, S. S., Wentzel, K. R., Weinberger, D. A., \& Munson, J. A. (1990). Marital satisfaction of parents of preadolescent boys and its relationship to family and child functioning. Journal of Family Psychology, 4, 213 - 234.

*Fincham, F. D., Beach, S. R. H., \& Bradbury, T. N. (1989). Marital distress, depression, and attributions: Is the marital distress-attribution association an artifact of depression? Journal of Consulting and Clinical Psychology, 57, 768 - 771.

*Fincham, F. D., Beach, S. R. H., Harold, G. T., \& Osborne, L. N. (1997). Martial satisfaction and depression: Different causal relationships for men and women? Psychological Science, 8, 351 - 357.

Fincham, F. D., \& Bradbury, T. N. (1987). The assessment of marital quality: A reevaluation. Journal of Marriage and the Family, 49,797 - 809.

*Fincham, F. D., \& Bradbury, T. N. (1993). Marital satisfaction, depression, and attributions: A longitudinal analysis. Journal of Personality and Social Psychology, 64, 442 - 452.

Foley, S. H., Rounsaville, B. J., Weissman, M. M., Sholomaskas, D., \& Chevron, E. (1989). Individual versus conjoint interpersonal therapy for depressed patients with marital disputes. International Journal of Family Psychiatry, 10, 29 - 42.

*Franks, M. M., Hong, T. B., Pierce, L. S., \& Ketterer, M. W. (2002). The association of patients’ psychological well-being with self and spouse ratings of patient health. Family Relations, 51, 22 - 27.

*Freudiger, P. (1983). Life satisfaction among three categories of married women. Journal of Marriage and the Family, 45, 213 - 219.

*Gavazzi, S. M., McKEnry, P. C., Jacobson, J. A., Julian, T. W., \& Lohman, B. (2000). Modeling the effects of expressed emotion, psychiatric symptomatology, and marital quality levels on male and female verbal aggression. Journal of Marriage and the Family, 62, 669 - 682.

Giddens, A. (1992). The transformation of intimacy. Stanford, CA: Stanford University Press. 
Glass, G. V., McGaw, B., \& Smith, M. L. (1981). Meta-analysis in social research. Beverly Hills, CA: Sage.

Glenn, N. D. (1998). The course of marital success and failure in five American 10-year marriage cohorts. Journal of Marriage and the Family, 60, 569 - 577.

*Glenn, N. D., \& Weaver, C. N. (1981). The contribution of marital happiness to global happiness. Journal of Marriage and the Family,43, 161 - 168.

*Gotlib, I. H., Lewinsohm, P. M., \& Seeley, J. R. (1998). Consequences of depression during adolescence: Marital status and marital functioning in early adulthood. Journal of Abnormal Psychology, 4, 686 - 690.

Hammen, C. L. (1991). The generation of stress in the course of unipolar depression. Journal of Abnormal Psychology, 100, 555 -561.

Hedges, L. V., \& Olkin, I. (1985). Statistical methods for meta-analysis. San Diego, CA: Academic Press.

Hedges, L. V., \& Vevea, J. L. (1998). Fixed- and random-effects models in metaanalysis. Psychological Methods, 3, 486 - 504.

Helms, H. M., \& Demo, D. H. (2005). Everyday hassles and family stress. In P. C.McKenry \& S. J.Price (Eds.), Families and change: Coping with stressful events (3rd ed., pp. 355 - 378). Thousand Oaks, CA: Sage.

*Henderson, A. D., Sayger, T. V., \& Horne, A. M. (2003). Mothers and sons: A look at the relationship between child behavior problems, marital satisfaction, maternal depression, and family cohesion. Family Journal, 11, $33-41$.

*Hoekstra-Weebers, J. E. H. M., Jaspers, J. P. C., Kamps, W. A., \& Klip, E. C. (1998). Marital dissatisfaction, psychological distress, and the coping of parents of pediatric cancer patients. Journal of Marriage and the Family, 60, 1012 - 1021.

*Horneffer, K. J., \& Fincham, F. D. (1995). Construct of attributional style in depression and marital distress. Journal of Family Psychology, 9, 186 - 195.

*Horwitz, A. V., White, H. R., \& Howell-White, S. (1996). Becoming married and mental health: A longitudinal study of a cohort of young adults. Journal of Marriage and the Family, 58, 895 - 907.

Huston, T. (2000). The social ecology of marriage and other intimate unions. Journal of Marriage and the Family, 62, 298 - 319. 
*Jacobson, N. S., Fruzetti, A. E., Dobson, K., Whisman, M., \& Hops, H. (1993). Couple therapy as a treatment for depression II: The effects of relationship quality and therapy on depressive relapse. Journal of Consulting and Clinical Psychology, 61, 516 - 519.

*Johnson, D. R., \& Booth, A. (1990). Rural economic decline and marital quality: A panel study of farm marriages. Family Relations,39, 159 - 165.

*Johnson, S. L., \& Jacob, T. (1997). Marital interactions of depressed men and women. Journal of Counseling and Clinical Psychology, 1, 15 - 23.

*Kahn, J., Coyne, J. C., \& Margolin, G. (1985). Depression and marital disagreement: The social construction of despair. Journal of Social and Personal Relationships, 2, 447 - 461.

Karney, B. R. (2001). Depressive symptoms and marital satisfaction in the early years of marriage: Narrowing the gap between theory and research. In S. R. H.Beach (Ed.), Marital and family processes in depression: A scientific foundation for clinical practice (pp.45 - 68). Washington, DC: American Psychological Association.

*Karney, B. R., Bradbury, T. N., Fincham, F. D., \& Sullivan, K. T. (1994). The role of negative affectivity in the association between attributions and marital satisfaction. Journal of Personality and Social Psychology, 66, 413 - 424.

*Kerns, R. D., \& Turk, D. C. (1984). Depression and chronic pain: The mediating role of the spouse. Journal of Marriage and the Family, 46, 845 - 852.

*Kim, H. K., \& McKenry, P. C. (2002). The relationship between marriage and psychological well-being. Journal of Family Issues, 23,885 - 911.

*Kurdek, L. A. (1991). Marital stability and changes in marital quality in the newlywed couples: A test of the contextual model. Journal of Social and Personal Relationships, 8, 27 - 48.

*Kurdek, L. A. (1998). The nature and predictors of the trajectory of change in marital quality over the first 4 years of marriage for first-married husbands and wives. Journal of Family Psychology, 12, 494 - 510.

*Kurdek, L. A. (1999). The nature and predictors of the trajectory of change in marital quality for husbands and wives over the first 10 years of marriage. Developmental Psychology, 35, 1283 - 1296.

*Kurdek, L. A. (2002). Predicting the timing of separation and marital satisfaction: An eightyear prospective longitudinal study.Journal of Marriage and Family, 64, 163 - 179.

*Kurdek, L. A. (2003). Negative representations of the self/spouse and marital distress. Personal Relationships, 10, 511 - 534. 
*Lavee, Y., Sharlin, S., \& Katz, R. (1996). The effect of parenting stress on marital quality. Journal of Family Issues, 17, 114 - 135.

*Lee, G. R. (1988). Marital satisfaction in later life: The effects of nonmarital roles. Journal of Marriage and the Family, 50, 775 - 783.

*Lev-Wiesel, R., \& Amir, M. (2003). The effects of similarity versus dissimilarity of spouses’ traumatic childhood events on psychological well-being and marital quality. Journal of Family Issues, 24, 737 - 752.

Lewis, R. A., \& Spanier, G. B. (1982). Marital quality, marital stability, and social exchange. In F. I.Nye (Ed.), Family relationships:Rewards and costs (pp. 49 - 65). Beverly Hills, CA: Sage.

Light, R. J., \& Pillemer, D. B. (1984). Summing up: The science of reviewing research. Cambridge, MA: Harvard University Press.

*MacEwen, K., \& Barling, J. (1993). Type A behavior and marital satisfaction: Differential effects of achievement striving and impatience/irritability. Journal of Marriage and the Family, 55, 1001 - 1010.

*Marchand, J. F., \& Hock, E. (2000). Avoidance and attacking conflict-resolution strategies among married couples: Relations to depressive symptoms and marital satisfaction. Family Relations, 49, 201 - 206.

*Merikangas, K. R., Prusoff, B. A., Kupfer, D. J., \& Frank, E. (1985). Marital adjustment in major depression. Journal of Affective Disorders, 9, 5 - 11.

*Meyers, S. A., \& Landsberger, S. A. (2002). Direct and indirect pathways between adult attachment style and marital satisfaction.Personal Relationships, 9, 159 - 172.

Moberg, P. J., \& Lazarus, L. W. (1990). Psychotherapy of depression in the elderly. Psychiatric Annals, 20(2), $92-96$.

O’Leary, D. A., Riso, L. P., \& Beach, S. R. (1990). Attributions about the marital discord/depression link and therapy outcome.Behavior Therapy, 21, 413 - 422.

*O’Leary, K. D., Christian, J. L., \& Mendell, N. R. (1994). A closer look at the link between marital discord and depressive symptomatology. Journal of Social and Clinical Psychology, 13, $33-41$.

*Orbuch, T. L., House, J. S., Mero, R. P., \& Webster, P. S. (1996). Marital quality over the life course. Social Psychology Quarterly, 59,162 - 171. 
Overton, R. C. (1998). A comparison of fixed-effects and mixed (random-effects) models for meta-analysis tests of moderator variable effects. Psychological Methods, 3, 354 - 379.

*Papp, L. M., Cummings, E. M., \& Schermerhorn, A. C. (2004). Pathways among marital distress, parental symptomatology, and child adjustment. Journal of Marriage and Family, 66, $368-384$.

Peterson, R. A., \& Brown, S. P. (2005). On the use of beta coefficients in meta-analysis. Journal of Applied Psychology, 90, 175 - 181.

*Proulx, C. M., Helms, H. M., \& Payne, C. C. (2004). Wives' domain-specific “marriage work” with friends and spouses: Links to marital quality. Family Relations, 53, 393 - 404.

*Rogers, S. J., \& DeBoer, D. D. (2001). Changes in wives’ income: Effects on marital happiness, psychological well-being, and the risk of divorce. Journal of Marriage and Family, 63, 458 472.

*Rohrbaugh, M. J., Cranford, J. A., Shoham, V., Nicklas, J. M., Sonnega, J. S., \& Coyne, J. C. (2002). Couples coping with congestive heart failure: Role and gender differences in psychological distress. Journal of Family Psychology, 16, 3 - 13.

Rosenthal, R. (1984). Meta-analytic procedures for social research. Beverly Hills, CA: Sage.

Rosenthal, R. (1991). Meta-analytic procedures for social research. Beverly Hills, CA: Sage.

Ross, C. E. (1995). Reconceptualizing marital status as a continuum of social attachment. Journal of Marriage and the Family, 57,129 - 140.

*Sacco, W. P., \& Phares, V. (2001). Partner appraisal and marital satisfaction: The role of selfesteem and depression. Journal of Marriage and Family, 63, 504 - 513.

*Sandberg, J. G., \& Harper, J. M. (1999). Depression in mature marriages: Impact and implications for marital therapy. Journal of Marital and Family Therapy, 25, 393 - 406.

*Schaefer, E. S., \& Burnett, C. K. (1987). Stability and predictability of quality of women's marital relationships and demoralization.Journal of Personality and Social Psychology, 53, $1129-1136$.

*Schafer, R. B., Wickrama, K. A. S., \& Keith, P. M. (1996). Self-concept disconfirmation, psychological distress, and marital happiness.Journal of Marriage and the Family, 58, 167 177.

*Schafer, R. B., Wickrama, K. A. S., \& Keith, P. M. (1998). Stress in marital interaction and change in depression: A longitudinal analysis. Journal of Family Issues, 19, 578 - 594. 
*Scott, R. L., \& Cordova, J. V. (2002). The influence of adult attachment styles on the association between marital adjustment and depressive symptoms. Journal of Family Psychology, 16, 199 - 208.

*Senchak, M., \& Leonard, K. E. (1993). The role of the spouses’ depression and anger in the attribution-marital satisfaction relation.Cognitive Therapy and Research, 17, 397 - 409.

Shadish, W. R., \& Haddock, C. K. (1994). Combining estimates of effect size. In L.Cooper \& L. V.Hedges (Eds.), The handbook of research synthesis (pp. 261 - 284). New York: Russell Sage.

*Simpson, J. A., Rholes, W. S., Campbell, L., Tran, S., \& Wilson, C. L. (2003). Adult attachment, the transition to parenthood, and depressive symptoms. Journal of Personality and Social Psychology, 84, 1172 - 1187.

*Smolen, R. C., Spiegel, D. A., Khan, S. A., \& Schwartz, J. F. (1988). Examination of marital adjustment and marital assertion in depressed and nondepressed women. Journal of Social and Clinical Psychology, 7, 284 - 289.

*Smolen, R. C., Spiegel, D. A., \& Martin, C. J. (1986). Patterns of marital interaction associated with marital dissatisfaction and depression. Journal of Behavioral and Experimental Psychiatry, 17, 261 - 266.

*Steinberg, L., \& Silverberg, S. B. (1987). Influences on marital satisfaction during the middle stages of the family life cycle. Journal of Marriage and the Family, 49, 751 - 760.

Sterne, J. A. C., Egger, M., \& Smith, G. D. (2001). Investigating and dealing with publication and other biases. In M.Egger, G.Davey Smith, \& D.Altman (Eds.), Systematic reviews in health care: Meta-analysis in context (2nd ed., pp. 189 - 208). London: BMJ.

*Stravynski, A., Tremblay, M., \& Verreault, R. (1995). Marital adjustment and depression. Psychopathology, 28, 112 - 117.

*Strazdins, L., \& Broom, D. H. (2004). Acts of love (and work): Gender imbalance in emotional work and women's psychological distress. Journal of Family Issues, 25, 356 - 378.

Thompson, L., \& Walker, A. J. (1989). Gender in families: Women and men in marriage, work, and parenthood. Journal of Marriage and the Family, 51, 845 - 871.

*Uebelacker, L. A., Courtnage, E. S., \& Whisman, M. A. (2003). Correlates of depression and marital dissatisfaction: Perceptions of marital communication style. Journal of Social and Personal Relationships, 20, 757 - 769.

*Ulrich-Jakubowski, D., Russell, D. W., \& O’Hara, M. W. (1988). Marital adjustment difficulties: Cause or consequence of depressive symptomatology? Journal of Social and Clinical Psychology, 7, 312 - 318. 
Vaillant, C. O., \& Vaillant, G. A. (1993). Is the U-shaped curve of marital satisfaction an illusion? A 40-year study of marriage. Journal of Marriage and the Family, 55, 230 - 240.

*Vanfossen, B. E. (1981). Sex differences in the mental health effects of spouse support and equity. Journal of Health and Social Behavior, 22, 130 - 143.

*Vega, W. A., Kolody, B., \& Valle, R. (1988). Marital strain, coping, and depression among Mexican-American women. Journal of Marriage and the Family, 50, 391 - 403.

*Voss, K., Markiewicz, D., \& Doyle, A. B. (1999). Friendship, marriage, and selfesteem. Journal of Social and Personal Relationships,16, 103 - 122.

*Voydanoff, P., \& Donnelly, B. W. (1999). Multiple roles and psychological distress: The intersection of the paid worker, spouse, and parent roles with the role of the adult child. Journal of Marriage and the Family, 61, 725 - 738.

*Ward, R. A., \& Spitze, G. (1998). Sandwiched marriages: The implications of child and parent relations for marital quality in midlife.Social Forces, 77, 647 - 666.

*Waring, E. M., \& Patton, D. (1984). Marital intimacy and depression. British Journal of Psychiatry, 145, $641-644$.

Weissman, M. M. (1987). Advances in psychiatric epidemiology: Rates and risks for major depression. American Journal of Public Health, 77, 445 - 451.

*Whisman, M. A. (1999). Marital dissatisfaction and psychiatric disorders: Results from the national comorbidity survey. Journal of Abnormal Psychology, 108, 701 - 706.

Whisman, M. A. (2001). The association between depression and marital dissatisfaction. In S. R. H.Beach (Ed.), Marital and family processes in depression: A scientific foundation for clinical practice (pp. 3 - 24). Washington, DC: American Psychological Association.

Whisman, M. A., \& Bruce, M. L. (1999). Marital distress and incidence of major depressive episode in a community sample. Journal of Abnormal Psychology, 108, 674 - 678.

*Wickrama, K. A. S., Lorenz, F. O., Conger, R. D., \& Elder, G. H., Jr. (1997). Marital quality and physical illness: A latent growth curve analysis. Journal of Marriage and the Family, 59, 143 - 155.

*Windle, M., \& Dumenci, L. (1997). Parental and occupational stress as predictors of depressive symptoms among dual-income couples: A multilevel modeling approach. Journal of Marriage and the Family, 59, 625 - 634. 